\title{
ETNOGRAFIA DE RUA: ESTUDO DE ANTROPOLOGIA URBANA
}

\author{
Ana Luiza Carvalho da Rocha
}

Cornelia Eckert

Walter Benjamin (1892-1940) ${ }^{1}$ inspirou-se na obra de Charles Baudelaire (1821-1867)2, e de Marcel Proust (1871-1922) ${ }^{3}$ para falar de um estado de ser e estar no mundo ao refletir sobre seus deslocamentos nas cidades de Berlim ou Paris, a partir de um "trabalho" da memória afetiva e do pensar a «si-mesmo» ${ }^{4}$ na paisagem urbana.

O personagem baudelairiano, o flâneur, caminha na cidade: um percurso sem compromissos, sem destino fixo. $\mathrm{O}$ estado de alma deste personagem-tipo é de indiferença, mas seus passos traçam uma trajetória, um itinerário que concebe a cidade, o movimento urbano, a massa efêmera, o processo de civilização. Logo, esta não é uma caminhada inocente. A cidade é estrutura e relações sociais, economia e mercado; é política, estética e poesia. A cidade é igualmente tensão, anonimato, indiferença, desprezo, agonia, crise e violência.

Assim, a cidade do andarilho tem uma história, nem a melhor nem a pior do mundo, simplesmente histórias que configuram referências práticas e simbólicas em que se reconhece ou se constrange nas ruas que perambula, lugares que conhece ou desconhece, espaços que gosta ou desgosta, contextos que lhe atraem ou passam desapercebidos. Objetos, eventos não verbais ou verbais, ruídos ou matérias atiram-lhe a atenção sensorial que delineia seu trajeto, seus atos. A cidade acolhe seus passos, e ela passa a existir na existência deste que vive, na instância de seu itinerário, um traçado que encobre um sentido, algo que será desvendado ao seu final. Espaços, cheiros, barulhos, pessoas, objetos e naturezas que o caminhante experiencia em sua itinerância, não sem figuras pré-concebidas. Sua caminhada é de natureza egocêntrica, funcional, mas também poética, fabulatória e afetiva, e por que não dizer, uma caminhada cosmológica como os jogos de memória que os tempos reencontrados proustinianos encenam.

Walter Benjamin, em seu texto Sur quelques thèmes baudelairiens (Paris, 1939), lembra que a multidão metropolitana na formação do mundo industrial despertava medo, repugnância e horror naqueles que a viam pela primeira vez. Da mesma forma, o impacto das transformações

\footnotetext{
${ }^{1}$ Referimo-nos principalmente a Das Passagen-Werk, escrito em 1939 à Paris e publicado em 1982.

${ }^{2}$ Referimo-nos basicamente aos trabalhos Le spleen de Paris e Tableaux parisiens.

${ }^{3}$ Referimo-nos sobretudo a $A$ la recherche du temps perdu, 1954.

${ }^{4}$ Ricoeur, 1996.
} 
urbanas, tão bem tratadas no conjunto de autores que de modo geral são reunidos na denominação Escola de Chicago, irá inspirar uma geração de antropólogos que privilegia, desde então (anos 1930), o tema do viver na cidade como cenário primordial de análise das mudanças e transformações.

Sob a ótica destes autores, a vida citadina é, portanto, agitada, vertiginosa mesmo, ou monótona e repetitiva, dependendo da adesão ou não dos seus habitantes aos tempos e espaços vividos, ritmados pelos movimentos incessantes das imagens de cidade que habitam seus pensamentos em constante mutação. Descrever a cidade, sob um tal ponto de vista, é conhecê-la como locus de interações sociais e trajetórias singulares de grupos e/ou indivíduos cujas rotinas estão referidas a uma tradição cultural que as transcende. Conhecer uma cidade é, assim, não só apropriar-se de parte de um conhecimento do mundo, ou seja, os saberes e fazeres dos habitantes e o que conheço desta experiência de pesquisa junto a eles, quanto desvendar o conhecimento na busca de situar meu próprio ser em relação ao ser do Outro na cidade.

Inspiradas nas obras científicas ${ }^{5}$ e literárias $^{6}$ sobre o "passear e caminhar", a idéia de desenvolver etnografias na rua nasceu com a proposta de projeto de pesquisa ${ }^{7}$ intitulado «Estudo antropológico de itinerários urbanos, memória coletiva e formas de sociabilidade no mundo urbano contemporâneo». Como pesquisadoras e, desenvolvendo a atividade de formar bolsistas de iniciação científica ao método antropológico, propomos ao aluno tecer os seus próprios percursos etnográficos na cidade de Porto Alegre, contexto de uma investigação antropológica sobre a dinâmica das interações cotidianas e representações sociais "na" e "da" cidade. No decorrer desta experiência etnográfica na rua, no bairro, na cidade, a introdução de instrumentos audiovisuais como a câmera fotográfica e/ou a câmera de vídeo, passam a fazer parte do seu olhar e atitude de coleta de dados de pesquisa: o exercício de etnografia de rua, inclui então, "a câmera na mão". ${ }^{8}$

\footnotetext{
${ }^{5}$ Referimo-nos entre outros à Claude Lévi-Strauss, Colette Pétonnet, Pierre Sansot.

${ }^{6}$ Citamos igualmente aqui as obras literárias de Henri Beyle Stendhal, Georges Perec, Italo Calvino e Ernest Hemingway.

${ }^{7}$ Projeto integrado Cnpq desenvolvido no Programa de pós-graduação em Antropologia Social na UFRGS, desde 1997, e que alimenta com dados de pesquisa o projeto Banco de Imagens e Efeitos Visuais, por nos coordenado, no âmbito do PPGAS/UFRGS, sediado no ILEA/UFRGS).

${ }^{8}$ Citamos como exemplos os seguintes trabalhos: ABREU DA SILVEIRA, Flávio. "A poética do vivido: uma etnografia do cotidiano na Cidade Baixa/POA/RS". In: Iluminuras: Série do Banco de Imagens e Efeitos Visuais. Porto Alegre: BIEV, PPGAS/UFRGS, 2000; BUAES, Aline Greff. "Etnografia de uma catástrofe. Estudo de antropologia urbana e visual sobre os desafios da natureza e a sobrevivência como modo de vida entre moradores de Águas Claras, Viamão". In: : Iluminuras: Série do Banco de Imagens e Efeitos Visuais. Porto Alegre: BIEV, PPGAS/UFRGS, 2001. Pibic/CNPq- UFRGS; COCCARO,
} 
A etnografia consiste em descrever práticas e saberes de sujeitos e grupos sociais a partir de técnicas como observação e conversações, desenvolvidas no contexto de uma pesquisa. Interagindo-se com o Outro, olha-se, isto é, "ordena-se o visível, organiza-se a experiência" conforme propõe Régis Debray9 . O etnógrafo descreve, tradicionalmente em diários, relatos ou notas de campo, seus pensamentos ao agir no tempo e espaço histórico do Outro-observado, delineando as formas que revestem a vida coletiva no meio urbano. A etnografia de rua, aqui, é um deslocamento em sua própria cidade, o que significa dizer, dentro de uma proposta benjaminiana, que ela afirma uma preocupação com a pesquisa antropológica a partir do paradigma estético $^{10}$ na interpretação das figurações da vida social na cidade. Um investimento que contempla uma reciprocidade cognitiva como uma das fontes de investigação, a própria retórica analítica do pesquisador em seu diálogo com o seu objeto de pesquisa, a cidade e seus habitantes. Uma vez que tal retórica é portadora de tensões entre uma tradição de pensamento científico e as representações coletivas próprias que a cidade coloca em cena, o pesquisador constrói o seu conhecimento da vida urbana na e pela imagem que ele com-partilha, ou não, com os indivíduos e/ou grupos sociais por ele investigados.

Luciane. "As donas da praça: estudo antropológico de formas de sociabilidade na praça da matriz". In: Iluminuras: Série do Banco de Imagens e Efeitos Visuais. Porto Alegre: BIEV, PPGAS/UFRGS, 2001. Bic Cnpq 1997/1999; DEVOS, Rafael. "Da arte de dizer: prá vê como a vida reserva tanta coisa prá gente". In: Iluminuras: Série do Banco de Imagens e Efeitos Visuais. Porto Alegre: BIEV, PPGAS/UFRGS, 2000. Bic Cnpq 1998/2000; JACOMINI, Jacques Xavier. "Estudo antropológico de um espaço urbano singular, o cais do porto da cidade de Porto Alegre (ou da cidade que tem porto até no nome)." In: Iluminuras: Série do Banco de Imagens e Efeitos Visuais. Porto Alegre: BIEV, PPGAS/UFRGS, 2001. Bic Cnpq 19971999; MELLO MERCIO, Rodrigo. "Moinhos de Vento: .Tão longe tão perto... , quando a exclusão social se traveste em constrangimento, o vizinho não reconhecido. In: Iluminuras: Série do Banco de Imagens e Efeitos Visuais. Porto Alegre: BIEV, PPGAS/UFRGS, 2001. Bic UFRGS/CNPq 2000; MYLIUS, Leandra. "Significações do viver na cidade: Um percurso afetivo e um olhar lógico, descrição de uma etnografia de rua na Osvaldo Aranha, Bairro Bonfim em Porto Alegre/RS". In: Iluminuras: Série do Banco de Imagens e Efeitos Visuais. Porto Alegre: BIEV, PPGAS/UFRGS, 2001. Bic Cnpq 1999/2001; PINHEIRO MACHADO, Rosana. "Estudo antropológico das formas de sociabilidade do centro de Porto Alegre: Vida de Camelô". In: Iluminuras: Série do Banco de Imagens e Efeitos Visuais. Porto Alegre: BIEV, PPGAS/UFRGS, 2000. Bic Fapergs 1999/2001; RAMALHO MARQUES, Olavo. "A cidade e o tempo: as transformações no cenário urbano em Porto Alegre". In: Iluminuras: Série do Banco de Imagens e Efeitos Visuais. Porto Alegre: BIEV, PPGAS/UFRGS, 2000. Bic UFRGS/Cnpq 1999/2001; RILLO, Sandro Belloli. "A cidade e os seus riscos: o viver de deficientes visuais em Porto Alegre". In: Iluminuras: Série do Banco de Imagens e Efeitos Visuais. Porto Alegre: BIEV, PPGAS/UFRGS, 2001. Bic Fapergs; RODOLPHO, Patrícia. "Encontrando imagens na e da Rua da Praia: problemas e descobertas de uma etnografia urbana". In: Iluminuras: Série do Banco de Imagens e Efeitos Visuais. Porto Alegre: BIEV, PPGAS/UFRGS, 2000. Bit Cnpq 1997/1999; SANTOS, João de los. "Ruinas e tragédia: um estudo sobre temporalidades em Porto Alegre." In: Iluminuras: Série do Banco de Imagens e Efeitos Visuais. Porto Alegre: BIEV, PPGAS/UFRGS, 2001. Bic Fapergs.

9 "L'image tire son sens du regard, comme l'écrit de la lecture, et ce sens n'est pas spéculatif mais pratique". Segundo

Debray, 1992: 56.

${ }^{10}$ Lembramos aqui o trabalho de Michel Maffesoli, 1985. 
A pretensão de aprofundar uma prática de "etnografia de rua" para o caso da pesquisa em Porto Alegre, ou talvez fosse melhor dizer etnografia «na» rua, não se limita apenas aos comentários de Walter Benjamin. A proposta singular de observation flottante, como Colette Pétonnet $^{11}$ denominou o exercício de observação de pesquisa na rua, encontra em nós, uma adesão de estilo pela forma como pensamos, no referido projeto, o tema da etnografia da duração $^{12}$ a partir da descrição etnográfica dos itinerários dos grupos urbanos na cidade.

Segundo advogamos na pesquisa sobre memória coletiva, narrativas e formas de sociabilidade no mundo contemporâneo, a técnica de etnografia de rua consiste na exploração dos espaços urbanos a serem investigados através de caminhadas «sem destino fixo» nos seus territórios. A intenção não se limita, portanto, apenas a retornar o olhar do pesquisador para a sua cidade por meios de processos de reinvenção/reencantamento de seus espaços cotidianos, mas capacitá-lo às exigências de rigor nas observações etnográficas ao longo de ações que envolvem deslocamentos constantes no cenário da vida urbana.

\section{Postulando uma carta de Porto Alegre, bairros, ruas, praças e esquinas}

Tornar-se «um» com os ritmos urbanos é perder-se no meio da multidão, se deixar possuir por alguma esquina, fundir-se nos encontros fortuitos, mas é também localizar-se nas conversas rápidas dos habitantes locais, registrar piscadelas descompromissadas dos passantes, rabiscar apressadamente um desenho destas experiências no seu bloco de notas, «bater» algumas fotos, gravar algumas cenas «estando lá». Desenhos, croquis, anotações, fotos, vídeos etc. No dizer bachelardiano, para se praticar uma boa etnografia de rua o pesquisador precisa aprender a pertencer a este território como se ele fosse sua morada, lugar de intimidade e acomodação afetiva, através dos devaneios do repouso ${ }^{13}$.

Uma etnografia de rua propõe ao antropólogo, portanto, o desafio de experienciar a ambiência das cidades como a de uma «morada de ruas» cujos caminhos, ruídos, cheiros e cores a percorrer sugerem, sem cessar, direções e sentidos desenhados pelo próprio movimento dos

\footnotetext{
${ }^{11}$ Pétonnet, 1982.

${ }^{12}$ Eckert e Rocha, 2000: pp. 19-40.

${ }^{13}$ Bachelard, 1989.
} 
pedestres e dos carros que nos conduzem a certos lugares, cenários, paisagens, em detrimento de outros.

Deslocamentos marcados por uma forma de apropriação dinâmica da vida citadina, mas cuja apreensão pauta-se pela frequiência sistemática do etnógrafo a uma rua ou uma avenida, um bairro ou uma esquina, etc.. Neste sentido a etnografia "na" rua consiste no desenvolvimento da observação sistemática de uma rua e/ou das ruas de um bairro e da descrição etnográfica dos cenários, dos personagens que conformam a rotina da rua e bairro, dos imprevistos, das situações de constrangimento, de tensão e conflito, de entrevistas com habitués e moradores, buscando as significações sobre o viver o dia-a-dia na cidade.

Fruto de uma adesão irrestrita do etnógrafo a uma ambiência urbana, escolha movida por amor ou ódio, à primeira vista ou não, pouco importa, a etnografia de rua, por insistência recorrente à poética do andarilho, ao explorar/inventariar o mundo na instabilidade do seu movimento, descobre um patrimônio intangível de formas que tecem as interações sociais num lugar. Assim, o ato simples de andar torna-se estratégia para igualmente interagir com a população com as quais cruzamos nas ruas. Habitués, freqüentadores, ou simples passantes, todos eles convidam o etnógrafo a perfilar personagens, descrever ações e estilos de vida a partir de suas performances cotidianas. E todos são bons momentos para se re-traçar os cenários onde transcorrem suas histórias de vida e, a partir deles, delinear as ambiências das inúmeras províncias de significados que abrigam os territórios de uma cidade.

Através da técnica da etnografia de rua, pode-se argumentar, o antropólogo observa a cidade como objeto temporal, lugar de trajetos e percursos sobrepostos, urdidos numa trama de ações cotidianas. Percorrer as paisagens que conformam um território, seguir os itinerários dos habitantes, reconhecer os trajetos, interrogar-se sobre os espaços evitados, é evocar as origens do próprio movimento temporal desta paisagem urbana no espaço.

A cidade torna-se, assim, aos olhos do etnógrafo, um território fluído e fugaz em alusão "a unidade de uma sucessão diacrônica de pontos percorridos, e não a figura que esses pontos formam num lugar supostamente sincrônico ou acrônico". ${ }^{14}$

Mas para se apreender a cidade como matéria moldada pelas trajetórias humanas, e não apenas como mero traçado do deslocamento indiferente de um corpo no espaço, o antropólogo precisa recompor os traços aí deixados por homens e mulheres. Uma etnografia de rua não se

\footnotetext{
${ }^{14}$ De Certeau. 1984.
} 
sustenta como prática antropológica de investigação sem contemplar, desde seu interior, uma reflexão sobre o forte componente narrativo que encerra os deslocamentos humanos capaz de metamorfosear «a articulação temporal dos lugares em uma seqüência espacial de pontos". ${ }^{15}$

Para se atingir um tal componente narrativo, o etnógrafo precisa contar com o tempo como amigo pois ele só o atinge quando a densidade de sobreposição cumulativa dos tempos vividos ao longo de um trabalho de campo, aparentemente fadado à «perda de tempo», se precipita diante dos seus olhos. Horas de um trabalho persistente de escritura depositadas na tela do computador, fitas de vídeo, películas fotográficas ou folhas de papel, sempre na tentativa do investigador aprisionar o efêmero, são, finalmente, recompensadas e encontram, enfim, um sentido desvendados por um leque de conceitos.

Sem dúvida, na etnografia de rua o perfil de uma comunidade, indivíduo e/ou grupo se configura aos poucos pois o etnógrafo trabalha pacientemente a partir de colagens de seus fragmentos de interação. Isto porque uma cultura urbana se expressa não só por convenções gestuais, de linguagens recorrentes, especializações profissionais de seus portadores, mas se apresenta igualmente através de suas práticas ordinárias, saberes e tradições com as quais o pesquisador precisa familiarizar-se neste deslocamento em espaços que são, ou não, o seu próprio lugar de origem.

$\mathrm{Na}$ busca do encontro e diálogos menos fortuitos que aqueles que os deslocamentos na rua permitem ao etnógrafo, a cumplicidade dos pequenos gestos, sorrisos ou olhares dos habitantes da rua, moradores locais, comerciantes, freqüentadores, mendigos, vendedores ambulantes, menino(a)s de rua, feirantes, pode significar um convite a aproximação mais duradoura. Nestes rituais de sedução e jogos de conquista da atenção do Outro, desvenda-se a lógica da criação dos papéis através dos quais constroem-se os personagens do antropólogo e do «nativo» ${ }^{16} \mathrm{em}$ interação.

Assim, ao lado das observações sistemáticas dos lugares de sociabilidade de rua, das suas intensidades segundo os diferentes horários, o comportamento corporal dos indivíduos e/ou grupos nas esquinas, suas formas de interação nos bares e bancos de praças, suas regras de evitações ou, ainda, as suas formas de cumprimentar ao cruzarem os olhares nas calçadas, tudo,

\footnotetext{
${ }^{15}$ De Certeau. 1984.

16 A noção de "nativo" é o termo técnico para definir o OUTRO na interação de pesquisa de campo, não abrigando mais os preconceitos da origem conceitual do mundo colonizado, mas aportando uma consciência histórica a nominação
} 
enfim, vai criando sentido na observação atenta do pesquisador a medida que ele se desloca. Esta caminhada vai sendo enriquecida em sua densidade temporal na medida em que o pesquisador consegue precisar, nas constâncias de suas diversas idas e vindas, os aspectos de permanência e mudança que caracterizam e dão forma estética a este território urbano. Aos poucos, os movimentos das pessoas, freqüentadores ou passantes se desenham em formas múltiplas, mas constantes, através de micro-eventos da própria rua observados meticulosamente pelo etnógrafo graças à perspectiva comparativa de uma atenção flutuante na observação sistemática da vida social.

Apesar de uma presença freqüente aos lugares, da insistência para ser visto e reconhecido pelo olhar do Outro, na etnografia de rua o contato nasce sempre de um pedido de consentimento à interação e troca possíveis que se seguem ao reconhecimento dos movimentos, olhares, ruídos locais, códigos e etiquetas a serem observadas e à aceitação da comunicação solicitada.

Entretanto, o pesquisador que vivencia a dramática da rua está sujeito a conhecer uma diversidade de micro-eventos de interação a qual ele próprio interage ou reage conforme a situação experienciada. O contato, sempre o contato, expressa o desejo de uma multiplicidade de trocas com os «nativos», pois é a reciprocidade, sem dúvida, a razão de ser e existir deste analista da diversidade e complexidade cultural. Nesta interação, ele depende não só do domínio da língua do Outro para compreender o que é dito, mas a atenção aos tons e meios tons, das insinuações e dos silêncios, dos não-ditos e refusas. Sem dúvida, o contato nasce deste processo de ritualização do estar na rua quotidianamente.

Sugere-se aqui que os personagens do etnógrafo e do "nativo" nascem, ambos, numa relação que é construída a partir de uma circunstância artificial provocada, provocativa e, por vezes provocatória, porque jamais natural. A construção do contexto do encontro etnográfico nutre-se destes códigos apreendidos pelo antropólogo na sua observação constante de si e do Outro, muitas vezes sob o fogo cruzado da situação de interação tanto quanto de negociação de realidade. Em todas elas, os atos que unem os antropólogos aos nativos assumem formas e graus diversos de sentido por suas especializações e desempenhos de papéis frente a eles.

Tomando-se a pesquisa dos dramas sociais e performances que encerra o teatro da vida urbana mediada pelo uso de recursos audiovisuais, estes dados levantados através do exercício de etnografia de rua, podem ajudar aqui na reflexão das implicações do antropólogo como intérprete de sua teia de significados. O uso da fotografia ou do vídeo na perspectiva do registro dramático, 
e mesmo dramatúrgico, das interações entre indivíduos e/ou grupos na cidade permitem ao etnógrafo aprofundar o estudo das formas de sociabilidade no mundo contemporâneo sob a

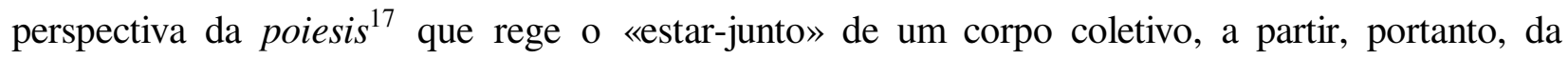
expressão compartilhada de determinado tipo comportamento estético entre os moradores e/ou habitués de um mesmo bairro, rua ou prédio de apartamentos.

Em especial, o recurso sistemático do vídeo nas etnografias de rua tem nos forçado a refletir sobre o papel estratégico da imagem-movimento não apenas como modalidade de registro, no tempo, do processo de inserção do antropólogo em campo (seus dilaceramentos), mas como parte do seu processo de interpretação dos atos de destruição/reconstrução das formas de vida social nas modernas cidades urbano-industriais, e de onde emerge a evidência da escritura etnográfica como construção da inteligência narrativa do próprio antropólogo.

Neste sentido, no âmbito do desenvolvimento de um projeto sobre estudos de narrativas como fonte de pesquisa para documentários etnográficos sobre a memória coletiva em Porto Alegre (desde 1997) e em Paris (2001), recorre-se à técnica de "etnografia na rua" como mais um exercício que permite ao etnógrafo não apenas reconhecer e interpretar o "nativo", mas igualmente interpretar o seu si-mesmo no contexto do diálogo com o Outro.

Se a etnografia de rua se apoia no uso de recursos audiovisuais, como câmeras de vídeo ou fotografia, o olhar do antropólogo por vezes assume um lugar de destaque. E se, em muitos momentos se é a situação de interação que irá introduzir o uso do equipamento audiovisual no trabalho de campo, em outros é a câmera de vídeo ou a máquina fotográfica que irá inserir o antropólogo no seu lugar de pesquisa.

No primeiro caso, o equipamento confirma o gesto da pesquisa naquilo que é captado como vivido humano no presente, seja o seu próprio, seja dos nativos, e mesmo de ambos. No segundo caso, as imagem registradas de instantâneos, quase sempre autorizadas, algumas até mesmo roubadas, não são apenas testemunhas do passado do «eu estive lá» do antropólogo. Elas podem exprimir o desejo expresso do nativo de ver-se «lá», eternizado na imagem capturada pelo olhar do antropólogo. ${ }^{18}$

\footnotetext{
${ }^{17}$ Ricoeur. 1994: pp. 55-76.

18 Os habitantes das grandes cidades, e mesmo de certos lugares urbanos como feiras, praias, etc; estão suficientemente familiarizado com o mundo tecnológico da mídia, compreendendo-se cada vez mais como atores do mundo social e não apenas expectadores passivos, desenvolvendo já há algum tempo sua própria forma de veicular a imagem de si aos olhos dos outros (pesquisadores, jornalistas, cineastas, etc.)
} 
A inclusão da máquina fotográfica ou câmera de vídeo na etnografia de rua não significa um ato compulsório, mas quando for o caso, a sua adoção, exige um certo conhecimento das regras dos códigos de ética para o seu uso, conforme aceitação por parte dos nativos uma vez que o registro de imagens de pessoas e situações no mundo urbano contemporâneo responde a direitos civis e disposições jurídicas e legais. ${ }^{19}$

Atentas a questão ética em torno da fixação do olhar etnográfico pela imagem fotográfica e/ou videográfica, pode-se dizer que o uso de recursos audiovisuais durante uma etnografia de rua é uma intervenção que ora faz parte da caminhada de reconhecimento do antropólogo do seu lugar de pesquisa, ora configura-se como um momento de intervenção consentida pelos personagens já contatados. Sob este ângulo, o potencial interpretativo da imagem etnográfica já se apresenta no próprio contexto de interação que cria a sua situação de captação uma vez que o triunfo da imagem, fotográfica ou videográfica, no trabalho de campo revela este frágil instante em que o pesquisador ousa inscrever uma ruptura na interação com o Outro. ${ }^{20}$

Neste ponto, fica evidente que a proximidade etnógrafo/nativo na rua é possível sempre que a presença da câmera é aceita pelos sujeitos pesquisados. Não raro, os próprios nativos são convidados a manusear a câmera (seja fotografia, seja vídeo) registrando em imagens o mundo que lhe rodeia a partir de sua própria perspectiva, dependendo é claro, de um tempo mais ou menos longo da equipe no contexto da pesquisa de campo.

Imagem impressa num negativo, acomodada num papel ou transferida para a memória do computador, fotos coloridas ou preto e branco, decisão de enquadramentos, definição da velocidade (tempo), regulagem do diafragma, etc. a técnica exige um aprendizado que não se processa sem que haja por parte do etnógrafo mediações conceituais. Em ambos os casos, fotografia ou vídeo, o processo posterior da descrição etnográfica, no diário de campo, associado ao da decoupage edição das imagens tornam-se um rico processo de avaliação reflexiva da

\footnotetext{
${ }^{19}$ Por exemplo, a imagem de um estabelecimento comercial tem que ser anteriormente concedida, mesmo que seja só a fachada; a foto e a imagem de uma pessoa facilmente identificada tem que ser autorizada pela mesma, mesmo que o uso desta imagem seja restrita ao universo da academia sem interesse comercial ou de mercado. Ocorre que hoje cada vez mais os projetos "extra-muros" das universidades são possíveis. Convite para exposições em locais públicos e em programas de TV local podem ocorrer a posteriori e o pesquisador tem que estar respaldado juridicamente para a utilização das imagens produzidas no âmbito de sua pesquisa.

${ }^{20}$ A concordância do grupo é, sem dúvida, fundamental tanto quanto sua compreensão da existência dos direitos de imagem e seu aceite em assinar documento para transmissão eventual da obra universitária em ambiente televisivo.
} 
própria estética das imagens, distorcidas ou não, que habitam dos pensamentos do antropólogo em situação de pesquisa de campo. ${ }^{21}$

\section{Uma síntes do mundo Rue Faubourg du Temple e Rue de Belleville - Paris}

A oportunidade de desenvolver um pós-doutoramento em Paris, ao longo do ano 2001, nos criou a possibilidade de ampliarmos para o contexto parisiense os exercícios de etnografia de rua que vínhamos desenvolvendo em vários bairros de Porto Alegre. Em junho de 2001, dois meses após nossa chegada a Paris e uma estada de dois meses alojadas em apartamento de amigos, no XIII ${ }^{\text {ème }}$ arrondissement (definição pelo qual a cidade de Paris é dividida administrativamente em bairros) mudamos para nossa moradia alugada, um apartamento «deux pièce», situado na Rue de la Fontaine au Roi, no $11^{\circ}$ arrondissement, em edifício projetado pelo arquiteto Louis Fargon em 1894, conforme está inscrito no pórtico de entrada.

Lá estávamos nós, habitando um bairro parisiense «típico» em razão de sustentar uma tradição pluriétnica, tal qual tinha sido nossa proposta de trabalho de pós-doutoramento estruturada ainda em Porto Alegre. Na época, a proposta era desvendar a cidade de Paris a partir de uma pesquisa etnográfica sobre as formas tensionais de vida no seu contexto urbano, num ensaio comparativo com as situações por nós pesquisadas, no Brasil.

Recém chegadas ao bairro, e morando próximo a Place de la Republique, uma região considerada por muitos como território de cruzamentos culturais os mais diversos (o que lhe dá uma feição de desordem que nos lembra a paisagem urbana de determinadas áreas centrais dos grandes centros urbanos do Brasil), os primeiros dias no local foram de tímidos passeios nas cercanias da nova residência, percorrendo várias vezes as suas ruas mais próximas e confirmando as nossas representações a respeito das marcas da multietnicidade de sua paisagem, impressões tecidas durante cinco anos, quando vivíamos em Paris (Eckert de 1987/1991 e Rocha de 1990/1994), na época de realização do doutoramento.

\footnotetext{
${ }^{21}$ Para o caso do registro em vídeo, a equipe deve ser pequena para que seja possível, no contexto da rua, a conquista de uma proximidade e intimismo de troca do etnógrafo com os indivíduos e/ou grupo investigados, o que uma grande equipe não permite.
} 
A escolha de uma rua em especial no bairro nos foi sugerida por um «nativo» francês e parisiense. A Rue de Belleville (derivado do nome «belavista» por situar-se na segunda maior elevação de Paris, após Montmartre) nos foi apresentada como sendo uma das mais interessantes para explorarmos uma França «profunda» segundo nos confessara este "nativo" em referência a sua memória povoada de boas lembranças do «tempos de boemia» dos anos 1970 no local. A sugestão era um convite para retornarmos ao exercício reflexivo em torno das formas diferenciais de se «viver a cidade» que vínhamos fazendo no Brasil, agora a partir de nossa inserção em Paris.

Foi, portanto, com tais motivações iniciais que nos aventuramos nas nossas primeiras longas caminhadas pelas ruas que nascendo na Place de la Republique seguiam em continuidade até o limite da cidade: Rue Faubourg du Temple e Rue Belleville.

Mapa na mão, livros de história da cidade e do bairro, folders turísticos, álbuns de fotografias publicados, fichas de documentários assistidos sobre o bairro ${ }^{22}$, visitas a Internet a partir da palavra-chave "Rue de Belleville", recorremos a estes como instrumentos importantes para dar os contornos e contextos etnográficos iniciais dos traçados a serem percorridos. ${ }^{23}$

Nossas caminhadas iniciavam-se regularmente na Place de la République onde o trajeto da Rue Belleville tem o nome de Rue Faubourg du Temple e deste ponto, subindo em direção ao morro de Ménilmontant, sob os traços da linha de metrô Chatelet/Porte de Lilas, carrefour entre os arrondissement $\mathrm{X}^{\text {ème }}, \mathrm{XI}^{\text {ème }}, \mathrm{XIX}^{\text {ème }}$ e $\mathrm{XX}^{\text {ème }}$. Nos limites desta linha de metrô situam-se várias estações, inclusive, a estação de Belleville, território nos arredores da qual podemos ainda descobrir pequenos fragmentos da ambiência antiga do vilarejo que ali existiu, preferido por artistas e poetas desde o séc. XVIII, encantados com o ar «mais salubre»e as habitações mais populares que existiam no local.

No trecho em que esta rua traz o nome de Rue Faubourg du Temple, ela concentra inúmeras moradias residenciais misturadas a uma paisagem pontilhada de várias casas comerciais

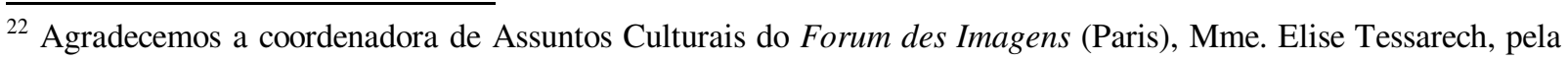
permissão concedida para pesquisarmos neste centro.

${ }^{23}$ Outra forma de conhecermos o lugar foi a busca de personagens que se dispusessem a falar sobre sua experiência de viver no lugar. A primeira personagem nasceu nesta rua, tem hoje 45 anos e vive na Alemanha, onde é casada e tem três filhos. Num encontro ocasional em julho de 2001, esta francesa se encanta com a informação que damos que desenvolvemos pesquisa na rua de Belleville, e nos diz "nunca imaginei que pudessem se interessar por esta rua tão pouco turística, mas para mim é uma surpresa agradável e tenho muitas coisas para te contar a respeito, pois nasci e cresci naquela rua, mas foram outros tempos". Tendo aceito ser entrevistada sobre o assunto, esta francesa nos recebe em sua residência na cidade de Munique, desfilando uma quantidade enorme de fotografias antigas guardadas de forma desordenada em caixas de camisas e sapatos.

Nossa outra informante é uma cineasta que vive em edifício localizado no cruzamento da rua Belleville com Jean Dumay, sindica de seu edifício.
} 
que se sucedem, tais como boutiques tipicamente francesas, açougues, um clube de lazer privado, cafés, padarias, fruteiras, livrarias, um cinema com filmes alternativos, lojas de aparelhos eletrônicos, etc. Na altura do Canal San Martin, esta mesma rua torna-se mais estreita. Na esquina da direita, um restaurante MacDonald's, e na da esquerda, um café tipicamente parisiense, parecem um pórtico de entrada para um mundo "das mil e uma noites". O comércio passa a ser dominado por proprietários de origem árabe com quinquilharias que avançam pela calçada buscando chamar a atenção do potencial cliente, além de algumas casas de produtos típicos do Paquistão, das Antilhas e da África.

Nas lojas de "quinquilharias" situadas no trecho descrito acima vendem-se mercadorias diversas por unidades. Faz-se esta observação para diferenciar este território daquele que contempla o comércio da Rue de Temple, situado do lado oposto à Place de la République, e onde os comerciantes, predominantemente de origem asiática, vendem à atacado. Neste local, as vitrines podem ser esteticamente fascinantes, mas, restrito ao atacado, a clientela é quase invisível, deixando as ruas vazias mesmo em dias de semana.

Ao contrário, na Rue Faubourg du Temple, torna-se extremamente difícil manter a caminhada em linha reta uma vez que, ao longo do percurso, somos surpreendidos por produtos e mercadores dispostos nas calçadas, disputando espaço com os pedestres. Calçadas sempre lotadas, seja em horário diurno ou noturno, deslocar-se nesta rua é estar no meio de uma pequena multidão que se acotovela e a palavra «pardon» é escutada aqui e lá.

A divisa entre a Rue Faubourg du Temple e a Rue de Belleville (trecho que constituía a principal rua do antigo vilarejo de Belleville), situa-se no cruzamento com as grandes avenidas denominadas Boulevard de la Villette e Boulevard de Belleville (esta última conhecida por abrigar o ponto turístico do Cemitério Père-Lachaise). Fechar os olhos nesta encruzilhada e ouvir os sons em diversas línguas, uma polifonia de vozes, nos desvendam atores dialogando em francês, árabe, chinês, africano, português nos fazendo lembrar da noção maussiana de mana na obra sobre a dádiva de Marcel Mauss, pois certamente este é um território onde misturam-se as almas e as coisas.

Um olhar mais atento às fachadas das casas comerciais, confirma o multilingüismo como marca local. Ao lado da indicação do estabelecimento escrito em francês, noblesse oblige, (boulangerie, pâtisserie, coiffeur) encontramos regularmente as informações traduzidas na escrita chinesa, árabe e turca, etc. Esta imagem de cruzamentos culturais é reforçada com a placa que 
anuncia a presença da filial Quick, fast-food americano, cercado pela ambiência fortemente européia de cafés tipicamente franceses, de um carrossel tradicional disputado por crianças, das padarias, confeitarias típicas e da fachada dos grandes prédios que se sucedem na rua.

\title{
Escolhemos um trecho de nossos diários de campo para descrever esta ambiência, ao
}

\author{
mesmo tempo, confusional e fusional.
}

«'Na rue de Belleville, em Paris, um viajante desavisado pode se sentir chocado com as surpreendente mistura étnica do bairro (3 junho 2001)'. Hoje, dia 17 de agosto, percorremos novamente a rue de Belleville e confirmamos que, as nossas primeiras impressões registradas no diário de campo, logo da nossa primeira caminhada nesta rua, no início de junho, não eram exageradas. Hoje, para se chegar neste «canto do mundo», não é preciso se deslocar de metrô, o sistema de transporte mais popular na cidade de Paris. Nossa residência não se situa muito longe deste território. O dia estava bom e convidativo para uma etnografia de rua, termo que adotamos, em 1997, para desenvolver exercícios de observação de itinerários urbanos na cidade de Porto Alegre. Aliás, ao sair de casa, na Rue de la Fontaine au Roi, pode-se dizer que estamos no território da multiplicidade étnica típica do bairro. Ainda na nossa rua, na quadra oposta ao nosso prédio, um restaurante senagelês, ao lado dele, um restaurante cubano e, seguindo-o, na mesma calçada, um restaurante tipicamente francês. Na esquina de nossa quadra, um bar com clientela que escuta em alto volume musicas cantadas em árabe ou tocadas com a popular guitarra argelina. Mistura de signos que anunciam a característica do bairro: uma torre de Babel, uma síntese do mundo. No curto percurso que se faz na Avenue Parmentier, antes de subirmos a Rue du Faubourg du Temple em direção à Rue de Belleville, podemos registrar alguns comércios dominados por hindus (ou serão paquistaneses?)? Estas lojas comerciais se sucedem, mercadinhos, barbearias, etc. Atravessamos, assim, este pequeno trecho da Avenue Parmentier, subindo a Rue Faubourg du Temple até o entroncamento da boulevard La Villete com a boulevard Belleville, que nos introduzem na Rue de Belleville. Neste carrefour tenho a tentação de fotografar tudo. Mas evitei neste momento em que queria estar atenta aos personagens da rua. Um grupo de três homens de origem hindu ou paquistanesa conversam na esquina, mas eles são minoria perto da quantidade impressionante de homens de origem argelina (ou serão magrebinos?) que se espalham nesta esquina. Parece uma manifestação, mas eles estão todos apenas conversando em local público, afirmando ser a rua o lugar masculino por excelência desta cultura. A presença destes personagens nos cafés de esquina é massivaa. Cumplicidade predominantemente masculina, sem dúvida. Tomam café, bebem cerveja e fumam muito as tradicionais 'narguilé', (cachimbos de origem persa). Vários grupos de homens se formam, os cumprimentos com beijos na face são freqüentes, lembrando ser este um costume não só francês mas também presente na cultura árabe. Os mais jovens parecem preferir um aperto de mãos, mas tudo indica a presença de relações de bairro ou de vizinhança, ou simplesmente 'habitués'. Ouve-se várias línguas possíveis com predominância do árabe. O movimento é incessante. Passam, caminham, tomam diversas direções provando que evocar os limites da rua é uma preocupação errônea. Num esforço, observamos quem são as mulheres nesta babilônia improvisada e percebemos que são as mulheres de origem africana vestidas a caráter e as mulheres de origem asiática que dominam as calçadas em atitude clara de compradoras de produtos diversos na imensidão de lojas e armazéns que dominam a Rua de Belleville». 
Sem dúvida, por inúmeros indícios, podemos afirmar que estamos num território parisiense, embora a estética urbana que predomine não é a da suntuosidade de uma França monárquica ou medieval, e mesmo de uma Paris haussmaniana como aquele que o turista insistentemente busca nos arrondissements $\mathrm{I}^{\text {ème }}$, IX ${ }^{\text {ème }}$ ou XVI ${ }^{\text {ème }}$. Na contramão do turismo de uma história monumental francesa, Belleville viveu e, ainda vive, sob outro ritmo temporal. Segundo apontam os livros de história da «velha Paris», nenhum outro canto da cidade conservou suas características campestres por mais tempo que Belleville.

Até fins do séc. XIX, a paisagem do bairro concentrava pedreiras, vinhedos, sítios, pomares, abatedores e algumas fábricas de manufaturas e armazéns, separados entre si por ruelas estreitas que se entrecruzavam, com larguras diversas, variando de $60 \mathrm{~cm} \mathrm{e} 2 \mathrm{~m}$, onde galinhas, patos, cães e pessoas disputavam seus espaços de vida, cercados por terrenos vagos, jardins abandonados, tavernas, cabarés e casas acinzentadas de dois andares, com corredores fechados por pequenas cercas de madeira em lugares. Um cenário que herdara os vestígios de ambiências de sociabilidades coletivas de outros tempos, época em que ali realizavam-se as famosas corridas de touros e a pitoresca festa do vinho com bebedeiras, orgias e badernas conhecidas e reconhecidas na memória dos parisienses como a época em que Paris tornava-se «Roma sem o Papa».

Segundo consta, ainda, em outros relatos que coletamos, o bairro nasce na paisagem urbana de Paris, acalentado por uma importante presença de movimentos de revoltas e conspirações populares que acompanharam a história francesa do séc. XIX. Uma história marcada pela agitação política que se termina com a supressão inteira da comuna de Belleville, em 1860, e, posteriormente, com a anexação de parte de seu território à região parisiense, recebendo, desde ai, em diferentes épocas, levas de imigração de diversas procedências cujas marcas pluriétnicas caracterizam o local. A forte presença recorrente destas camadas de diferentes tempos, através da referência do olhar etnográfico aos seus fragmentos e detalhes na paisagem urbana desta área do bairro, amalgamam-se no tempo presente de nossa caminhada.

Desde o início do empreendimento do exercício, portanto, fiéis à idéia de aprofundarmos as reflexões em torno da "etnografia de rua" como técnica destinada ao estudo dos itinerários 
urbanos e a memória coletiva no mundo contemporâneo, insistimos em caminhadas pela Rue de Belleville onde o destino final, em termos geográficos, pode ser considerado a Porte de Lilas, uma das portas que delimita a fronteira entre a cidade de Paris, organizada em 20 bairros, e a periferia de Paris, conhecida pelo nome de banlieue.

Em inúmeros pontos dos trajetos adotados para se atingir a Rue de Belleville, guiavam-nos algumas publicações destinadas a curiosos sobre as histórias registradas na memória dos bairros parisienses e de suas regiões limítrofes. Com estas intenções, nos deixamos levar por idas e vindas em ruelas que cortam a Rue de Belleville, e que nos conduziram a belas e boas surpresas, como foi o caso da descoberta do Parque de Belleville, cujo acesso por uma pequena ruela, a Rue Piat, bordada à direita, com algumas antigas árvores herdadas das velhas alamedas ali existentes, e que esconde dos passantes a «bela vista» da cidade de Paris que dali se pode ter, sem precisar disputar com nenhum turista o melhor ponto de visão.

Mantivemos caminhadas constantes na tentativa de se descobrir uma Belleville «no tempo de outrora» mas cujos indícios nos ligassem a atual Belleville. Esta foi a forma como tomávamos contato com os pequenos pedaços de paisagem que são quase invisíveis se comparados com a agitação da Rue de Belleville, como foi o caso da Rue de l'Hermitage. Nesta rua de traçado irregular, quase um beco, e que se situa à esquerda de quem desce a colina de Belleville, ainda se pode observar diminutos conjuntos arquitetônicos formados por aglomerados de antigos casarios, com seus jardins apertados por prédios de apartamentos. Todas estas casas baixas foram adaptadas às atividades de seus novos donos e/ou moradores, em geral artistas, num sinal da permanência da aura através da qual Belleville tornou-se conhecida na memória da cidade.

Mesmo na ausência da antiga Belleville e dos seus acidentes geográficos (fontes, pedreiras e poços) para nos situar na ambiência romântica do bairro, a cada nova saída insistíamos em levar conosco o atual mapa de Paris numa das mãos e, na outra, livros da «velha Paris» que narravam estórias pitorescas do lugar. Íamos, assim, caminhando a passos lentos, surpreendendo-nos aqui e acolá com os trajetos sinuosos das ruas que, vez por outra, cortavam, em zigue-zague, a Rue de Belleville, conduzindo-nos em direção ao topo do morro de Ménilmontant. 
Em outra ocasião, deslocando-nos à esquerda de quem sobe a Rue de Belleville, em direção da Place de Fêtes, atingimos, no coração do $\mathrm{XX}^{\mathrm{ème}}$ arrondissement, o Parque des Buttes Chaumont. O passeio havia sido programado no sentido de aproveitarmos, como moradoras do local, a ambiência tipicamente de lazer de fim-de-semana dos parques parisienses num quentíssimo dia de verão. Pais com seus filhos, casais de namorados, grupos de adolescentes, solitários empedernidos, cachorros e seus donos, vendedores de sorvetes, cata-ventos e balões, enfim, uma multidão de pessoas passeando, deitadas na grama dos jardins ou sentadas nos bancos acotovelavam-se para disputar um lugar ao sol. Recém chegadas do mais rigoroso verão tropical, ao contrário dos parisienses que acabavam de sair de um longo inverno cinzento, frio e chuvoso, apenas desejávamos uma sombra agradável protegidas do sol e do calor intenso que fazia naquele dia.

Nos deslocamentos constantes, nos divertíamos com o fato de estarmos ora no XIX ${ }^{\text {ème }}$ arrondissement, ora no $\mathrm{XX}^{\mathrm{ème}}$ arrondissement, uma alteração de posição no mundo que dependia de onde estávamos situadas, se de um ou de outro lado, esquerda ou direita de quem desce a Rue de Belleville. Uma divisão jurídico-administrativa que não alterava a paisagem da rua, e muito menos a feição do próprio bairro, assim como não produzia nenhum efeito de marcas diferenciais entre os estilos de vida dos moradores locais.

Nas caminhadas constantes, quase sempre a descoberta de pequenas ruelas e impasses como incidentes de percurso, marcaram nosso afastamento da Rue de Belleville. Num destes dias, aproveitamos a visita de uma colega, Elizabeth Lucas, para nos colocarmos como guias turísticos de seu deslocamento no bairro.

Optamos por subir a colina de Ménilmontant de ônibus, o «96», até as proximidades da Place de Saint Fargeau, ponto final de várias outras linhas de ônibus. Uma passageira brasileira que se encontrava no ônibus, ouvindo nossos comentários em língua portuguesa e sotaque brasileiro, identificou-se rapidamente como antiga moradora do bairro e

profunda conhecedora de seus hábitos e características, indicando-nos várias outras opções de trajetos que desconhecíamos. 
]O encontro foi um lembrete para nós de que ainda tínhamos um longo caminho de aprendizagens sobre os diversos territórios do bairro que permaneciam ainda invisíveis aos nossos olhos. Humildemente descemos do ônibus, caminhamos até a Rue des Pyrenées, e de lá iniciamos, então, a «descida» da Rue de Belleville pois estávamos no alto da colina. Pequenas ruelas sem saída nascem em perpendicular à Rue de Belleville. Aproximando-nos da igreja Saint Jean Baptiste de Belleville, prestávamos mais atenção a seqüência de edifícios, buscando aquele onde havíamos visto, em nossas primeiras incursões no local, uma placa anunciando que ali havia habitado a cantora francesa Edith Piaf, tendo, segundo biografias, nascido nas próprias escadarias que conduziam aos apartamentos, com a sua mãe em estado de embriaguez.

Na ocasião, "descer" a Rue de Belleville era percorrer o caminho inverso do que havíamos nos habituando a fazer quando deixávamos a nossa casa em direção ao bairro. Do topo do morro, esforçando-nos por olhar por cima da curva que esta rua desenha, primeiro à direita, e depois, em forma de "S", à esquerda, pode-se ter uma idéia dos motivos originais que deram este nome ao lugar. Posicionado quase no topo da colina, o etnógrafo-turista consegue uma belle vue da cidade, uma imagem fugaz da Tour Eiffel que é logo recortada, aqui e ali, pelo perfil das fachadas dos prédios de apartamentos que hoje ocupam a área. Visto de cima, sob o topo do plateau de Ménilmontant, de 117m, desce-se quase em linha reta até a Place de la République, um dos carrefours que liga em forma de estrela inúmeras ruas e avenidas que deságuam no $\mathrm{XI}^{\mathrm{e}}$ arrondissement.

No percurso de nossas etnografia de rua, em Bellevile, a interação com o Outro nem sempre é possível. Em alguns, ele é simplesmente provocado pela situação de pesquisa propriamente dita, em outros, este encontro procura se revestir do tom casual de nossas ações ordinárias no bairro como parte integrante de sua população de habitués, como descrevem os fragmentos do cotidiano etnográfico transcritos neste trecho de diário de campo que segue:

\footnotetext{
Para fotografar um contexto interno na rue Belleville, entramos num salão de beleza e tentamos estabelecer uma conversação com a proprietária e funcionárias, todas mulheres asiáticas. A proprietária não permitiu que eu fotografasse o local e para disfarçar meu constrangimento, optei por dizer que também estava lá para um corte de cabelo, buscando durante este tempo, explicar-me melhor. $\mathrm{O}$ que foi aceito sem nenhum entusiasmo, passando-me para uma jovem que não falava francês e indicava todas as ações que devia seguir com gestos e palavras soltas em chinês. O diálogo, em plena Paris, fora interrompido pela barreira da língua.
} 
Em ambos os momentos por nós assinalados acima, o «caminhar» do etnógrafo busca as diferenças entre o olhar da investigação e o olhar que orienta as caminhadas nos locais turísticos de Paris, onde este status, «turista», parece revestir a todos de uma certa proteção à crítica ou ao olhar reprovador. A foto autorizada ao turista, parece ser menos comprometedora de uma situação de inserção no local repleta de práticas ilegais e estratégias de sobrevivência, pressuposto que podemos exemplificar através deste relato:

Mais uma recusa para fotografar, desta vez um vendedor de castanhas parado na esquina da Place de la République. Um carrinho de supermercado é a "churrasqueira" provisória, onde um fogareiro com carvão em brasas esquentam as castanhas depositadas em uma chapa com furos. A reação do provável indiano foi taxativa, não! Aqui uma pressuposição passou a ganhar forma para nós: não é negligenciável o número de trabalhadores estrangeiros, principalmente vendedores ambulantes, em situação irregular. A fotografia se tornaria uma prova desta atividade ilegítima e por isto, em geral a foto "posada" é recusada. A negociação mais longa é impossível devido a barreira da língua, são trabalhadores que não falam francês e se escondem em seus segredos de comunidade étnica.

Uma outra parte extraída de nosso diário de campo ilustra esta forma «casual» de ocuparmos os lugares de vida urbana na Rue de Belleville tal qual apreendemos como «etnografia de rua» e como ela permite, por sua fluidez, que possamos nos aproximar do contexto urbano de grandes cidades como estes fossem verdadeiros «cantos do mundo»:

Ir às compras em Belleville, na tentativa de descobrir temperos e ingredientes para uma feijoada «à brasileira» é descobrir lojas de especiarias antilhesas e africanas. Lojas que procurei também levada pela necessidade de comprar certas bugigangas de plástico para a casa, e que no Brasil encontramos nos supermercados. Aqui, para comprar um balde, uma garrafa térmica, copos de vidro ou material elétrico vai-se nas lojas «dos árabes», se queremos comprar tecidos para cortinas e almofadas desloco-me até as lojas dos «indianos» e africanos, para renovar o estoque caseiro de molhos e chás, há os supermercado dos «chineses». Posso, se for o caso, «dar um pulo» no Monoprix, um supermercado «bon marché», com aparência de uma loja de departamentos, para ver as ofertas de vinhos e queijos franceses! Todas elas são sempre boas e nobres razões para percorrer a Rue de Belleville em seus mais diversos contextos, como se ali vivessemos há um bom tempo. Sem dúvida, ao final de cada ida à campo sempre acabo me interrogando sob a forma como a aparência caótica da rua não só agrada aos meus olhos de etnógrafa da desordem urbana, mas desafia o meu senso estético ao provocar a busca de um sentido para a diversidade tensional de cores, temperaturas, cheiros, texturas, tamanhos, formas dos produtos comercializados nestes lugares, tal qual as próprias pessoas que transitam por entre as prateleiras, corredores e calçadas de Bellevile. Um esforço reflexivo que vem sempre acompanhado do ato recorrente de me disfarçar no Outro, certamente na tentativa de encontrar ali, eu própria, o meu lugar de estrangeira em Paris, fazendo desta rua a minha casa natal.

Certamente, algumas convenções sociais na forma de habitar tais áreas de um bairro parisiense nos pareciam familiares, não só por já termos vivido na cidade de Paris para desenvolver programa de doutoramento, mas por compartilharmos de uma cultura urbana que, mesmo em se tratando de Brasil e de uma cidade da escala de Porto Alegre, cultiva o gosto pelo 
deslocamento no anonimato.

Entretanto, caminhar por Paris, nos limites traçados pela Rue de Bellevile nos remetia constantemente ao nosso encontro, como estrangeiras, com a multiplicidade de culturas e etnias denunciadas não apenas pelas diferenças entre tons de pele, cor dos olhos, tipos de roupas, de penteados e adereços, de expressões e gestos etc. dos habitantes locais, homens, mulheres ou crianças, moradores ou não. Havia igualmente a confrontação com as inúmeras sonoridades de voz com que o Outro se apresentava aos nossos olhos. Seja em árabe, chinês, vietnamita, hindu, yddish, seja nas línguas africanas que nos era difícil de precisar a origem, todas elas, ao mesmo tempo, neste espaço parisiense, nos incitavam constantemente à uma reflexão sobre nossa própria língua e cultura como estrangeiras ao lugar, apontando para o esforço de «vigilância epistemológica» a ser feito para ultrapassar tais barreiras. Um pequeno trecho de nosso diário de campo pode ilustrar este processo aqui apontado:

No dia 5 de outubro, o traçado percorrido não se diferencia muito de caminhadas anteriores. Caminhar pela Faubourg du Temple e pela Belleville é o objetivo, mas neste dia carregamos um aparelho fotográfico. A intenção maior é buscar a riqueza da multiplicidade étnica. Não é difícil cumprir este objetivo pois este é o contraste predominante. Lojas comerciais de origem árabe, judia, hindú, chinesa, vietnamita, cubana, etc, se vizinham numa aparente harmonia contrastando com o clima de conflito e tensão mundial entre as culturas orientais e ocidentais que a operação vigilânciapirata do governo francês em seu programa contra o terrorismo, busca acordar. Mas nestas ruas, nenhum policial se faz presente. As diversas etnias ali presentes certamente precisam recorrer as notícias da imprensa e televisão para lembrar que a chamada guerra americana ou ocidental contra o terrorismo acontece neste mesmo momento em algum lugar. Fotografamos vários estabelecimentos e situações na rua. Um vendedor ambulante de origem hindu vende milhos aquecidos no carvão. Não entendo de onde possa ser a origem deste hábito. Perguntamos para ele se podemos fotografar e ele consente, coisa rara pois em geral temem as fotos por serem trabalhadores irregulares. Mas o diálogo sobre a prática da venda do milho não prossegue, pois o vendedor não fala francês. Um outro senhor, parecendo ser de origem árabe, pergunta o que procuramos saber. Repito minha pergunta e devido meu forte sotaque ele interroga de onde venho? Respondo ser brasileira. O senhor, que entendi ser uma espécie de "fiscalizador" da possível aproximação de fiscais oficiais, pergunta se sou turista. Respondo que sim e delicadamente justifica não conhecer a origem do hábito de vender milho queimado. $\mathrm{O}$ que importa é que todos comprem. Lembramos que os franceses costumam vender castanhas da mesma forma, alimentação que os teria salvo da fome em diversas situações de guerra e de miséria. Seguimos nosso caminho sempre fotografando visando interações e a prova de que, em Paris, a estética urbana é a mistura de estilos.

Retomando-se os diários de campo para fins de análise, somos atraídas pela cultura polifônica tratada por Bakhtin ${ }^{24}$ e por seu conceito de heteroglossia visando dar conta, aqui, da 
capacidade de convivialidade plural em Belleville, das questões de identidade étnica, das tensões inerentes à multiplicidade de línguas, dialetos e sotaques falados, dos arranjos nas formas de sociabilidade locais e das inúmeras formas estéticas que se tecem segundo as múltiplas e complexas formas de interação, eventos efêmeros ou eventos cotidianos e habituais que nos apresentam os referentes urbanos em que o contexto social se ancora.

A apresentação de outro extrato do diário de campo pode aqui exemplificar, mais precisamente, o que dissemos acima:

No dia 5 de setembro, a caminhada como sempre foi iniciada na rue Faubourg du Temple. A intenção era seguir um traçado mais desordenado tendo esta rua e a de Belleville como referência, fazendo quase um zigue-zague. Na esquina com Boulevard de la Villette um grupo de seis pessoas formados de homens e mulheres, estão sentados na calçada com clara aparência de embriaguez. Parecem ser de origem francesa, repetindo uma tendência que observamos nas ruas parisienses: pessoas em geral de cor branca, na faixa de 30 a 50 anos, estão sentados em calçadas ou degraus de lojas consumindo muito álcool. Costumam ficar sempre no mesmo lugar, pedem dinheiro e frente a recusa dizem um simples «merci», ou mesmo um desaforo, certamente devido o estado de embriaguez. Neste dia não faz frio. Outros bancos são ocupados por homens provavelmente aposentados devido a aparência mais idosa. Portam típicos chapéus argelinos. Conversam em dupla ou pequenos grupos. Conversam em língua de origem, parecem tranquilos. Aparentemente jogam conversa fora para matar o tempo. Já a esquina com a boulevard Belleville, chama a atenção a quantidade de açougues judeus próximos a uma sinagoga. Os negócios estavam todos fechados com bilhetes escritos a mão anunciando os obséquios de um dos patrões.

O que vivemos nos percursos cotidianos é intensamente o movimento, a interação, as práticas cotidianas. A efemeridade da nossa passagem, entretanto, certamente nos impede de desvendar uma série de códigos locais, etiquetas, segredos, não ditos, gestos, olhares e ações que nos passam desapercebidos, e que apenas uma continuidade da pesquisa de campo neste espaço pode elucidar. Mas é a própria experiência de estranhamento/familiarização que esta sendo dramatizada. Aparências imediatas buscam ser ultrapassadas em parte pela imagens que retemos, pela fotografia, pelo vídeo, pela descrição no diário.

Em especial, no que se refere o uso dos recursos audiovisuais, nossa opção foi, neste momento, fotografar com uma câmera digital as cenas, personagens, situações e dramas que compunham a paisagem urbana de Belleville, como se reflete nesta passagem do diário de campo:

Neste dia, nosso deslocamento com a máquina parece não chamar a atenção pois a prática do turismo no local não é estranha aos moradores. A obscenidade que nosso olhar indiscreto possa provocar, parece não incomodar. A luz para tomada fotográfica é boa. Um típico dia de outono. O enquadramento é, ora no sentido horizontal, ora vertical. Pode-se observar que tendemos a enquadrar de forma retangular certamente devido a estreiteza da rua ea intenção de, neste momento, buscarmos mapear os espaços de continuidade das ruas. Fotografamos interações e cenários que para nos, traduzem as formas do lugar. Interagir com os habitantes foi um pouco mais frustrante. 
O uso sistemático da câmera fotográfica ou da câmera de vídeo nas caminhadas por estas ruas objetiva a reconstrução de uma narrativa a partir da própria temporalidade do registro da imagem no instante em que o acontecimento se desenrola sob nossos olhos, o que desencadeia a presença de todas as outras imagens que nos habitaram em momentos e situações anteriores quando o olho que registrava não era o da câmera, mas o olho humano repleto de pequenas impressões mnésicas, experiências sensoriais, evocação de imagens de outras cenas urbanas, em outros bairros, cidades e países.

Cenas evocadas pelo diário de campo, pela fotografia ou vídeo, pouco importa, tratam-se de imagens que nos habitam a medida em que nos deslocamos pelas ruas, avenidas, lojas, esquinas, etc. Da Paris de Hemingway à Paris de hoje, de Paris à Porto Alegre, e vice-versa, elas estão lá, conosco a exigir o rigor comparativo com as imagens apreendidas que dão sentido ao evento urbano propriamente dito que encerra a etnografia de rua, em Belleville. 


\section{Referencias}

BACHELARD, Gaston. (1989) La poétique de l'espace. Paris, Puf.

BACHELARD, Gaston. (1989) La terre et les rêveries du repos. Paris, José Corti.

BAKHTIN, Mikhail. (1992) Estética da criação verbal. São Paulo, Martins Fontes. BAUDELAIRE , Charles. (1861) Tableaux parisiens. Les fleurs du mal. Paris, Poulet-Malassis. BAUDELAIRE, Charles. (1869) Le spleen de Paris. Paris, Asselineau et Banville. BENJAMIN, Walter. (1982) Das Passagen-Werk, escrito em 1939 à Paris e publicado em 1982.

BENJAMIN, Walter. (1939) Sur quelques thèmes baudelairiens, in Zeitschrift für Sozialforschung, VIII,1, 2

Paris.

CALVINO, Italo. (1990) As cidades invisiveis. São Paulo, Companhia das Letras.

CANEVACCI, Massimo. (1993) A cidade polifônica. São Paulo, Studio Nobel.

DE CERTEAU, Michel. (1984) A invenção do quotidiano. Petrópolis, Vozes. DEBRAY,

Régis. (1992) Vie et mort de l'image. Paris, Gallimard.

ECKERT, Cornelia e ROCHA, Ana Luiza Carvalho da. (1998) "A interioridade da experiência temporal do

antropólogo como condição da produção etnográfica”. In: Revista de Antropologia. Volume 41, número $2 . \quad$ São

Paulo, Faculdade de Filosofia, Letras e Ciências Humanas, Universidade de São Paulo. pp. 107 à 135.

ECKERT, Cornelia e ROCHA, Ana Luiza Carvalho da. (2001) "Imagens do tempo nos meandros da memória : por uma etnografia da duração ». In : Koury, Mauro Guilherme Pinheiro (Org). Imagem e Memória, ensaios em Antropologia visual. Rio de Janeiro, Garamond.

GEERTZ, Clifford. (1989) El antropologo como autor. Barcelona, Paidos Studio. L'ÉCOLE DE

CHICAGO. (1974) Naissance de l'écologie urbaine. Paris, Aubié. LEVI-STRAUSS, Claude.

(1998) Tristes Trópicos, São Paulo, Companhia das Letras.

MAFFESOLI, Michel. (1985) "Le paradigme esthétique. La sociologie comme art". In: Sociologie et Société. Vol. XVII, Numero 2, octobre, pp. 33 à 39, Montréal, Ceaq.

MAUSS, Marcel. (1974) "Ensaio sobre a dádiva”. In: Sociologia e Antropologia. Volume II. São Paulo, EPU/EDUSP.

PETONNET, Collete. (1982) “L'observation flottante, l'exemple d'un cimetière parisien”. In: Revue

L'Homme, Octobre/Décembre, numéro XXII 4, pp. 37 à 47, Paris, CNRS.

PROUST, Marcel. (1954) Le temps retrouvé, vl. VIII de A la recherche du temps perdu. Paris, Gallimard. RICOEUR, Paul. (1994) Tempo e Narrativa. Vol I, SP, Papirus.

RICOEUR, Paul. (1996) Soi-même comme un autre. Paris, Ed. du Seuil. SANSOT, Pierre. (1972) Poétique de la ville. Paris, Klincksick. 